\title{
Qualidade da água de nascentes urbanas: estudo de caso em microbacia Amazônica, município de Ji-Paraná/RO
}

A consolidação dos núcleos urbanos de forma desordenada provoca alterações significativas nos fluxos hídricos das cidades, a exemplo da canalização de igarapés e emissão direta de esgotos e retirada da vegetação. Desta forma, o objetivo do estudo foi associar os impactos ambientais de nascentes urbanas do município de Ji-Paraná/RO com o uso e ocupação, mediante a análise de variáveis físico-químicas e microbiológicas da água. Foram selecionadas oito nascentes do igarapé Dois de Abril com diferentes condições de uso e ocupação, sendo este um afluente da bacia do rio Ji-Paraná, que por sua vez compõe a bacia Amazônica. Foram realizadas ao longo de um ano, análises laboratoriais da qualidade da água abrangendo as variáveis: Oxigênio Dissolvido (OD), pH, Turbidez, Resíduos Totais, Fósforo Total, Nitrato, Nitrito, Amônia, Coliformes Totais e Fecais. Foram identificados impactos negativos na qualidade da água em todas as nascentes. O OD esteve abaixo de $5 \mathrm{mg} / \mathrm{L} \mathrm{em}$ todas as nascentes, em pelo menos um dos períodos sazonais analisados, e mesmo as médias mais baixa de Fósforo Total foram superiores ao estabelecido pela Resolução CONAMA 357/05, que é $0,1 \mathrm{mg} / \mathrm{L}$, bem como o pH e Coliformes Totais que também estiveram em desconformidade com a norma.

Palavras-chave: Urbanização; Recursos Hídricos; Microbacias.

\section{Water quality of urban springs: a case study in Amazon microbacy, Ji-Paraná/RO municipality}

\begin{abstract}
The consolidation of the urban centers in a disorderly way causes significant changes in the water flows of the cities, for example the channeling of streams and direct emission of sewage and removal of vegetation. Thus, the objective of the study was to associate the environmental impacts of urban springs of the municipality of Ji-Paraná / RO with the use and occupation, through the analysis of physical-chemical and microbiological variables of water. From previous studies, eight springs of different conditions of use and occupation of the microbasin of the Dois de Abril stream were selected, being this one a small tributary of the Amazon basin. Water quality laboratory analyses were performed for one year on the parameters: Dissolved Oxygen (DO), pH, Turbidity, Total Residues, Total Phosphorus, Nitrate, Nitrite, Ammonia, Total and Fecal Coliforms. In general, negative impacts on the water quality of all sources were identified. DO was below 5 $\mathrm{mg} / \mathrm{L}$ in all springs in at least one of the analyzed seasonal periods, and even the lowest averages of Total Phosphorus were higher than that established by CONAMA Resolution 357/05, which is $0.1 \mathrm{mg} / \mathrm{L}$, as well as the $\mathrm{pH}$ and Total Coliforms that also were in disagreement with the standart.
\end{abstract}

Keywords: Urbanization; Water Resources; Micro-Basins.

Topic: Engenharia de Recursos Hídricos

Reviewed anonymously in the process of blind peer.

Decauita Poliana Peixoto da Silva (iD

Universidade Federal de Rondônia, Brasil http://lattes.cnpq.br/6809292331117372 http://orcid.org/0000-0002-1667-0346

decauita@gmail.com

Nara Luisa Reis de Andrade (1D)

Universidade Federal de Rondônia, Brasil http://lattes.cnpq.br/1976520958836915 http://orcid.org/0000-0001-8602-6161

naraluisar@gmail.com

Alberto Dresh Webler (iD

Universidade Federal de Rondônia, Brasil http://lattes.cnpq.br/2636465000898348 http://orcid.org/0000-0001-5777-2982

betowebler@gmail.com
Received: 12/04/2019

Approved: 27/05/2019
Referencing this:

SILVA, D. P. P.; ANDRADE, N. L. R.; WEBLER, A. D.. Qualidade da água de nascentes urbanas: estudo de caso em microbacia Amazônica município de Ji-Paraná/RO. Revista Ibero Americana de Ciências Ambientais, v.10, n.3, p.90-102, 2019. DOI:

http://doi.org/10.6008/CBPC2179-6858.2019.003.0009 


\section{INTRODUÇÃO}

As mudanças no uso do solo provocadas pelo processo desordenado de urbanização são fontes de impacto hidrológico negativo nos recursos hídricos (CUNHA et al., 2016). Dentre esses impactos pode-se citar a compactação, impermeabilização, desmatamento, aterramentos, entre outros (TUCCI, 2016). Além disso, nos centros urbanos está concentrada grande parte dos transtornos referentes à poluição dos recursos hídricos por águas residuais (MEDEIROS et al., 2017). Estima-se que países desenvolvidos tratem, em média, 70\% do esgoto industrial e municipal gerado (UNESCO, 2017), enquanto no Brasil esse índice é de cerca de 40\% (ANA, 2017).

Por esses motivos, em várias regiões do país estão sendo diagnosticados impactos na qualidade da água de igarapés urbanos, bem como na integridade do sistema ecológico aquático como um todo (CORDEIRO et al., 2016; CUNHA et al., 2016; SOUZA et al., 2017; SOUZA et al., 2014). Nesses ambientes os córregos de pequeno porte sofrem os impactos de forma mais intensa, visto que a malha urbana se torna uma fonte difusa de poluição atingindo o corpo hídrico de forma abrangente. Por esse motivo, as microbacias urbanizadas carecem maior atenção nos processos de gestão dos recursos hídricos.

Com esse objetivo, nas últimas décadas, ecologistas organizaram simpósios internacionais para abordar deficiências sobre a compreensão dos fluxos urbanos e ajudar a desenvolver estratégias de gestão eficazes (ROY et al., 2016). A partir do primeiro simpósio, ocorrido na Austrália em 2003, surgiu o conceito de Síndrome do Córrego Urbano, no qual se caracterizam os córregos urbanizados a partir de aspectos como hidrogramas mais rápidos, alta taxa de contaminantes na água, alterações da morfologia dos canais e baixa biodiversidade (CAPPS et al., 2016).

Na região Norte do Brasil, apesar da riqueza hídrica, um dos principais problemas é a precariedade do serviço de coleta e tratamento de esgoto (ANA, 2017). Estudos desenvolvidos na região têm indicado alterações nas características da água de igarapés e rios amazônicos por meio da análise de variáveis limnológicas (BEZERRA et al., 2014; BUTZKE et al., 2015; MEDEIROS et al., 2017; PEREIRA et al., 2016; ROBOREDO et al., 2016; ROCHA et al., 2018; SANTOS et al., 2017). No entanto, de forma geral as pesquisas e aspectos normativos não são direcionadas especificamente para áreas de nascentes (MARMONTEL et al., 2018).

Por definição, as nascentes são aflorações do lençol subterrâneo que formam os corpos hídricos e desempenham importante função na manutenção da vazão dos corpos hídricos superficiais nas épocas de estiagem. A conservação dos nascentes e pequenos córregos depende do manejo adequado da bacia hidrográfica de forma a priorizar a conservação do solo, das matas ciliares e zonas de recarga (MALAN et al., 2018; VALENTE et al., 2015).

Desta forma, é imprescindível o levantamento de informações quanto às condições ambientais dos mananciais, bem como de suas nascentes, tendo em vista que as nascentes são o ponto de partida para a conservação dos corpos hídricos e sofrem maiores impactos devido à sensibilidade frente às variações de uso do solo (MARMONTEL et al., 2018). O objetivo do estudo foi associar os impactos ambientais de diferentes 
nascentes urbanas de Ji-Paraná/RO com o seu uso e ocupação, mediante a análise de variáveis físicoquímicas e microbiológicas da água das nascentes.

\section{METODOLOGIA}

O município de Ji-Paraná está localizado no centro-leste do estado de Rondônia, região Amazônica. A precipitação anual total está entre 1660 mm a 2000 mm (GOMES et al., 2015). A hidrografia urbana é composta por 15 microbacias, sendo a microbacia do igarapé Dois de Abril a de maior dimensão $\left(5,5 \mathrm{~km}^{2}\right)$, dentre as que estão totalmente inseridas no perímetro urbano do município (CARMO et al., 2016), sendo este igarapé um afluente do rio Ji-Paraná. Pertencente à bacia Amazônica, o rio Ji-Paraná desagua no rio Madeira.

Tendo em vista que o igarapé em estudo possui cerca de 50 nascentes, foi realizada a identificação em campo do maior número possível de nascentes a fim de selecionar os pontos representativos para posterior monitoramento ambiental. A partir de estudos prévios foram localizadas e observadas in loco 35 nascentes, representando 70\% do total (SILVA et al., 2016), das quais foram selecionadas 8 nascentes com diferentes graus de uso e ocupação a fim de representar as condições da microbacia, conforme Figura 1.

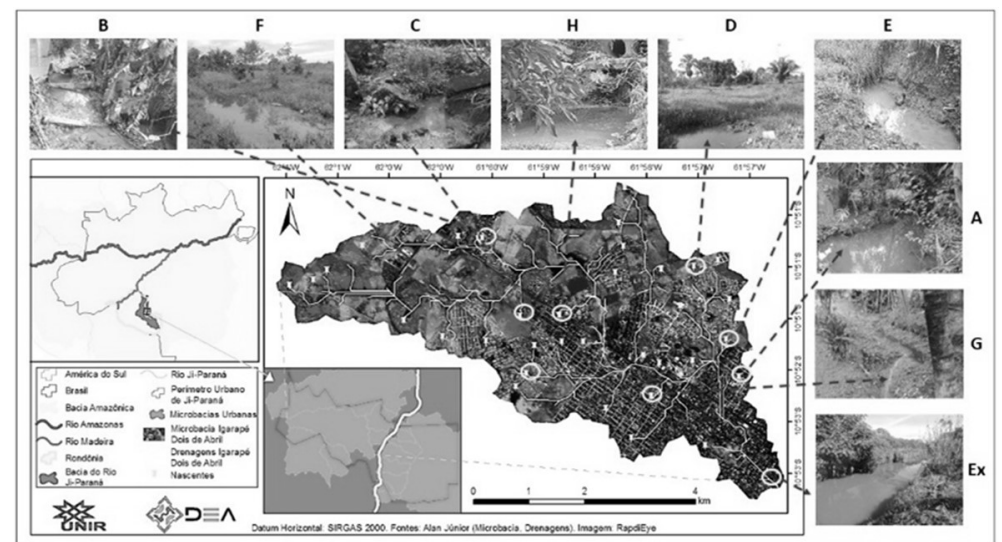

Figura 1: Localização da microbacia do Igarapé Dois de Abril e identificação das nascentes visitadas, Ji-Paraná/RO.

O Quadro 1 representa algumas das características macroscópicas que foram observadas nas nascentes selecionadas para estudo conforme metodologia sugerida por Gomes et al. (2005). A vazão foi obtida pelo cálculo do produto da velocidade de um objeto flutuante colocado na superfície da água pela área da seção molhada do córrego.

As coletas de amostras de água das nascentes foram realizadas entre julho de 2016 e junho de 2017, totalizando 12 coletas, garantindo assim a representatividade de um ano hidrológico. Além das nascentes foi selecionado para a coleta de amostras o exutório da microbacia localizado a menos de 50 metros da desembocadura do igarapé 2 de abril no rio Ji-Paraná/RO.

Os procedimentos laboratoriais para determinação das variáveis foram realizados de acordo com o estabelecido no Standard Methods for the Examination of Water and Wastewater (APHA) no laboratório de Microbiologia Limnologia e Microbiologia da Universidade Federal de Rondônia, campus de Ji-Paraná. Em casos complementares foi utilizado o método descrito na NBR $12.619 / 92$ para análise de nitrito; NBR 
12.772/92 para análise de Fósforo Total e NBR 10.664/89 para Resíduos Totais. O pH e a Temperatura foram obtidos em campo a partir do aparelho Sonda Portátil 221 Lutron e a Turbidez foi medida pelo turbidímetro de bancada DeltaLAb.

Quadro 1: Aspectos ambientais do entorno de nascentes monitoradas do igarapé Dois de Abril, Ji-Paraná/RO.

\begin{tabular}{|l|l|l|}
\hline Ponto & Vazão (L/s) & Aspectos macroscópicos \\
\hline A & 7,2 & $\begin{array}{l}\text { Distância de }>50 \mathrm{~m} \text { de residências; vegetação preservada: processo de revitalização em } \\
\text { desenvolvimento; emissão de esgotos não observada. }\end{array}$ \\
\hline B & 6,50 & $\begin{array}{l}\text { Próximo ao distrito industrial (<100m); vegetação preservada; grande quantidade de resíduos sólidos; } \\
\text { processos erosivos observados. }\end{array}$ \\
\hline C & 3,10 & Vegetação de buritizais; uso por bovinos; distante de residências (>300 m). \\
\hline D & 15,6 & Próximo <50 m de residências; buritizal e vegetação rasteira; \\
\hline E & 1,43 & $\begin{array}{l}\text { Proximidade <20m de residências; vegetação primária (capoeirão) e árvores frutíferas; emissão de } \\
\text { esgoto domiciliar; processos erosivos observados. }\end{array}$ \\
\hline F & 34,9 & Caraterística de zona rural: vegetação rasteira, uso por equinos; proximidade de <100 m de residências. \\
\hline G & $\begin{array}{l}\text { Não } \\
\text { identificada }\end{array}$ & $\begin{array}{l}\text { Proximidade de <4m de residências; vegetação totalmente degradada; emissão direta de esgoto } \\
\text { domiciliar; processos erosivos e aterramento observados. }\end{array}$ \\
\hline H & 14,9 & $\begin{array}{l}\text { Proximidade de <4m de residências; vegetação frutífera; emissão direta de esgoto de um } \\
\text { estabelecimento comercial. }\end{array}$ \\
\hline
\end{tabular}

Ao longo do processo de realização das análises laboratoriais, os dados foram tabulados e agrupados de acordo com os períodos sazonais da região descritos por Gomes et al. (2015), sendo estes: seca (julho a setembro), seca-cheia (outubro a dezembro), cheia (janeiro a março) e cheia-seca (abril a junho). Para a análise das diferenças entre os pontos amostrados e entre os períodos sazonais foi aplicado o teste de hipótese de Kruskal Wallis, com nível de significância de 0,05. Tal teste estatístico é utilizado quando se pretende testar a hipótese nula de que as amostras são provenientes de populações distintas. $\mathrm{O}$ fato desse ser um teste não paramétrico contribui para a viabilidade da aplicação do teste de hipótese em dados que não possuem distribuição normal (TRIOLA, 2013), como é caso dos dados obtidos no presente estudo.

\section{RESULTADOS}

Acerca dos resultados das análises físico-químicas e microbiológicas, na Figura 2 estão dispostas graficamente as médias das variáveis analisadas para cada nascente por período sazonal.
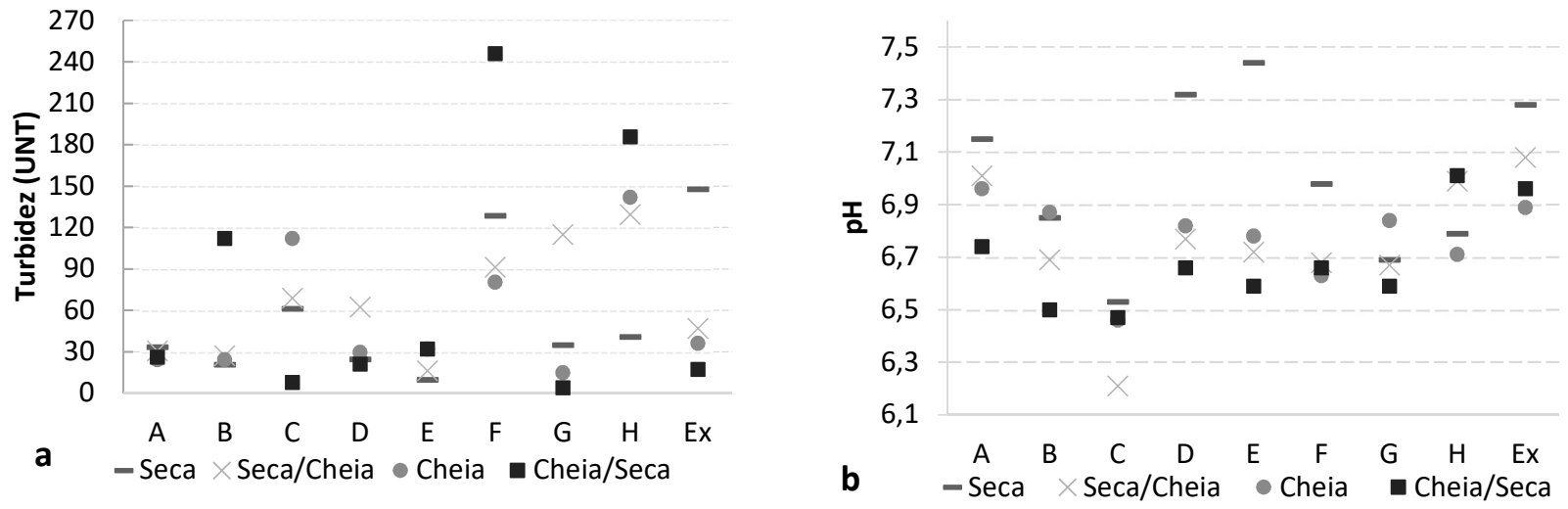


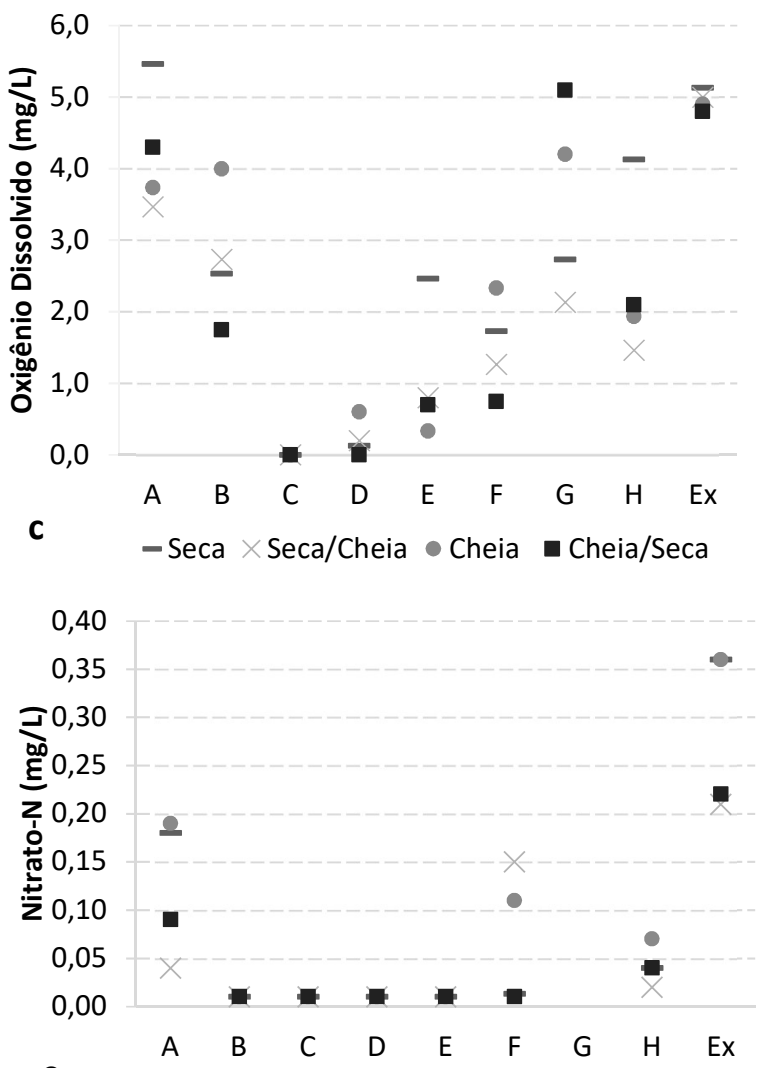

e $\quad$ Seca $\times$ Seca/Cheia - Cheia $\square$ Cheia/Seca

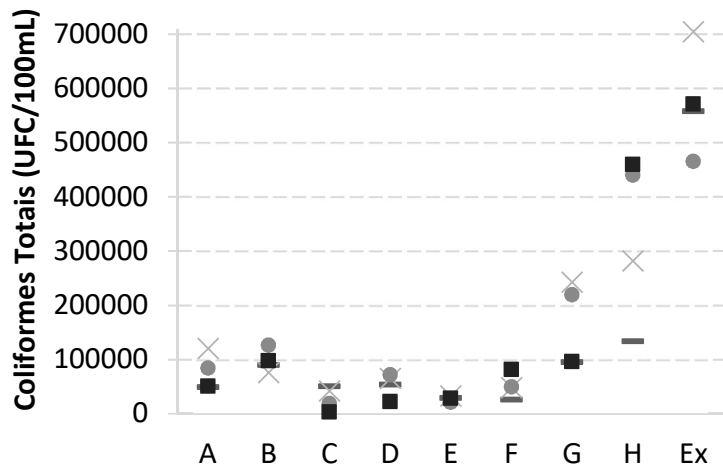

g - Seca $\times$ Seca/Cheia - Cheia $\square$ Cheia/Seca

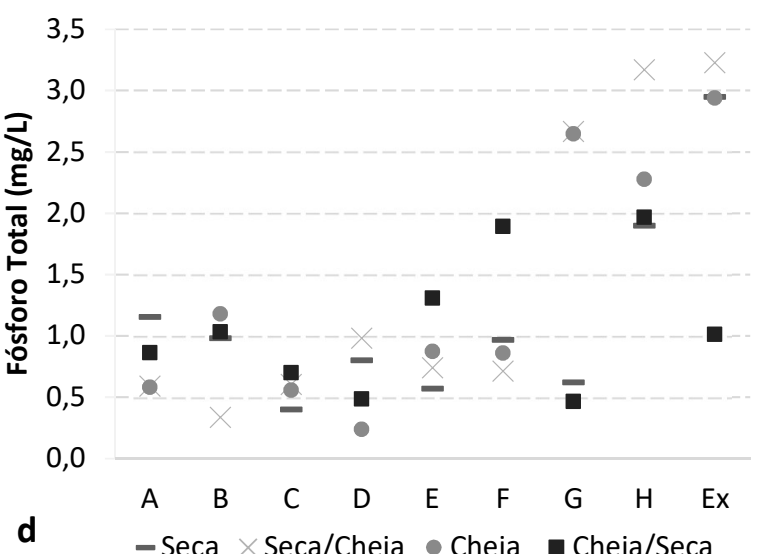

d $\quad-$ Seca $\times$ Seca/Cheia $\bullet$ Cheia $\square$ Cheia/Seca

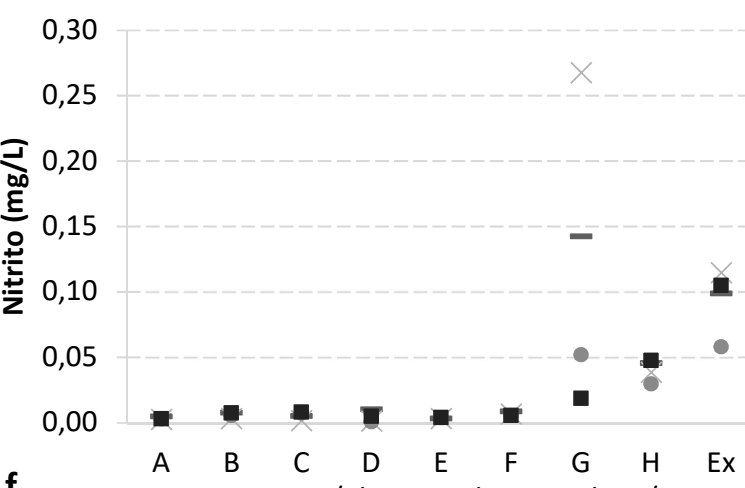

$\mathbf{f}$

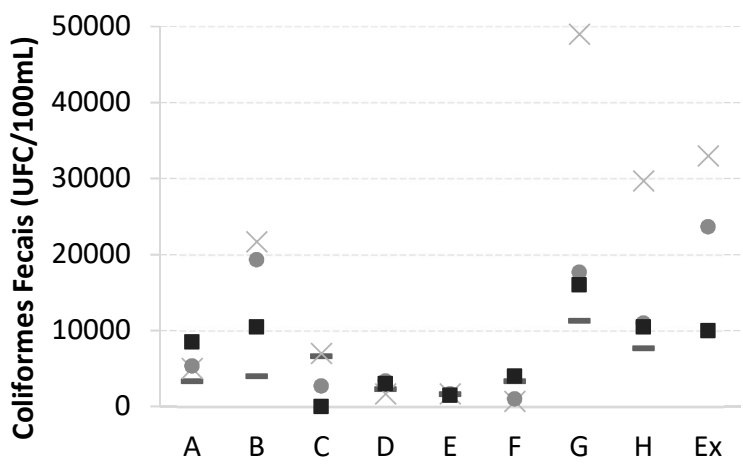

h - Seca $\times$ Seca/Cheia - Cheia $\square$ Cheia/Seca

Figura 2: Médias de Turbidez (a), pH (b), Oxigênio Dissolvido (c), Fósforo Total (d), Nitrato-N (f), Nitrito (g) Coliformes Totais (g) e de E.coli (h) de nascentes do Igarapé Dois de Abril, Ji-Paraná/RO.

Na Tabela 1 estão representados os valores de $\mathrm{p}$ ( $p$-valor) resultantes do teste de Kruskal Wallis. Para o cálculo foram utilizados todos os dados obtidos a fim de verificar as relações existentes entre as variáveis de qualidade da água das nascentes. Os valores referentes às mínimas e máximas das variáveis físicas Turbidez, Resíduos Totais e Temperatura são, respectivamente, 1,8 uN e 347 uN; 10 mg/L e $1104 \mathrm{mg} / \mathrm{L} ; 21^{\circ} \mathrm{C}$ e $28,9^{\circ} \mathrm{C}$. Para as variáveis químicas foram encontrados os valores mínimo e máximo de 6,06 e 8,11 para o pH; 0,1 mg/L e 6,6 mg/L de Oxigênio Dissolvido; 0,12 mg/L e 7,19 mg/L de Fósforo Total; 0,031 mg/L e 0,17 $\mathrm{mg} / \mathrm{L}$ de Nitrogênio Amoniacal; 0,01 mg/L e 14,75 mg/L de Nitrato; 0,001 mg/L e 0,53 mg/L de Nitrito. Em relação às variáveis microbiológicas, a densidade mínima de Coliformes Totais foi de 1000 UFC/100 mL e a densidade máxima foi de 498000 UFC/100 mL. Para os Coliformes Fecais (E.coli) a densidade mínima foi de 1000 UFC/100 mL e máxima de 115000 UFC/100 mL. 
Tabela 1: Resultados do teste de Kruskal Wallis (p-valor) para comparação entre nascentes do Igarapé Dois de Abril, JiParaná/RO, julho de 2016 a junho de 2017.

\begin{tabular}{|c|c|c|c|c|c|c|c|c|c|c|c|}
\hline Nascentes & Tur & RT & $T$ & $\mathrm{pH}$ & OD & FT & $\mathrm{Ni}$ & $\mathrm{Na}$ & $\mathrm{Am}$ & CT & CF \\
\hline$A-B$ & 0,97 & 0,07 & 0,99 & 0,91 & 0,26 & 0,95 & 0,99 & 0,00 & 0,00 & 0,82 & 0,97 \\
\hline$A-C$ & 0,97 & 0,03 & 0,02 & 0,01 & 0,00 & 0,95 & 0,99 & 0,02 & 0,01 & 0,06 & 0,32 \\
\hline$A-D$ & 0,97 & 0,25 & 0,99 & 0,91 & 0,00 & 0,95 & 1,00 & 0,00 & 0,72 & 0,38 & 0,31 \\
\hline$A-E$ & 0,97 & 0,98 & 0,08 & 0,91 & 0,00 & 0,95 & 1,00 & 0,00 & 0,72 & 0,14 & 0,15 \\
\hline A-F & 0,29 & 0,41 & 0,99 & 0,91 & 0,00 & 0,95 & 0,12 & 0,31 & 0,00 & 0,25 & 0,17 \\
\hline$A-G$ & 0,97 & 0,41 & 0,00 & 0,62 & 0,74 & 0,95 & 0,00 & 0,00 & 0,00 & 0,69 & 0,97 \\
\hline A-H & 0,08 & 0,00 & 0,99 & 0,91 & 0,10 & 0,37 & 0,00 & 0,33 & 0,00 & 0,04 & 0,97 \\
\hline A-Ex & 0,97 & 0,98 & 0,26 & 0,91 & 0,74 & 0,42 & 0,00 & 0,05 & 0,00 & 0,00 & 0,58 \\
\hline$B-C$ & 0,97 & 0,98 & 0,38 & 0,41 & 0,00 & 0,95 & 1,00 & 0,31 & 0,72 & 0,01 & 0,04 \\
\hline B-D & 0,97 & 0,98 & 0,99 & 0,91 & 0,00 & 0,95 & 0,32 & 0,00 & 0,03 & 0,10 & 0,04 \\
\hline B-E & 0,97 & 0,54 & 0,99 & 0,91 & 0,10 & 0,95 & 1,00 & 0,91 & 0,01 & 0,03 & 0,02 \\
\hline $\mathrm{B}-\mathrm{F}$ & 0,73 & 0,98 & 0,99 & 0,91 & 0,20 & 0,95 & 1,00 & 0,02 & 0,72 & 0,06 & 0,02 \\
\hline B-G & 0,97 & 0,98 & 0,04 & 0,91 & 0,74 & 0,95 & 0,00 & 0,00 & 0,72 & 0,82 & 0,97 \\
\hline B-H & 0,24 & 0,03 & 0,99 & 0,91 & 0,74 & 0,81 & 0,01 & 0,02 & 0,00 & 0,14 & 0,97 \\
\hline B-Ex & 0,97 & 0,98 & 0,99 & 0,91 & 0,10 & 0,91 & 0,00 & 0,00 & 0,03 & 0,01 & 0,97 \\
\hline C-D & 0,97 & 0,98 & 0,66 & 0,05 & 0,74 & 0,95 & 0,32 & 0,00 & 0,15 & 0,82 & 0,97 \\
\hline C-E & 0,97 & 0,27 & 0,99 & 0,14 & 0,20 & 0,95 & 1,00 & 0,60 & 0,04 & 0,82 & 0,97 \\
\hline C-F & 0,97 & 0,98 & 0,38 & 0,62 & 0,10 & 0,95 & 1,00 & 0,67 & 0,72 & 0,82 & 0,97 \\
\hline C-G & 0,97 & 0,98 & 0,99 & 0,91 & 0,00 & 0,95 & 0,00 & 0,00 & 0,72 & 0,00 & 0,00 \\
\hline $\mathrm{C}-\mathrm{H}$ & 0,95 & 0,08 & 0,86 & 0,03 & 0,00 & 0,03 & 0,01 & 0,67 & 0,00 & 0,00 & 0,08 \\
\hline C-Ex & 0,97 & 0,98 & 0,99 & 0,00 & 0,00 & 0,03 & 0,00 & 0,00 & 0,00 & 0,00 & 0,00 \\
\hline D-E & 0,97 & 0,98 & 0,99 & 0,91 & 0,39 & 0,95 & 1,00 & 0,00 & 0,72 & 0,82 & 0,97 \\
\hline D-F & 0,70 & 0,98 & 0,99 & 0,91 & 0,22 & 0,95 & 0,02 & 0,00 & 0,00 & 0,82 & 0,97 \\
\hline D-G & 0,97 & 0,98 & 0,09 & 0,91 & 0,00 & 0,67 & 0,00 & 0,00 & 0,01 & 0,00 & 0,00 \\
\hline $\mathrm{D}-\mathrm{H}$ & 0,23 & 0,01 & 0,99 & 0,91 & 0,00 & 0,01 & 0,00 & 0,00 & 0,00 & 0,00 & 0,07 \\
\hline D-Ex & 0,97 & 0,98 & 0,99 & 0,91 & 0,00 & 0,02 & 0,00 & 0,00 & 0,00 & 0,00 & 0,00 \\
\hline$E-F$ & 0,02 & 0,98 & 0,99 & 0,91 & 0,74 & 0,95 & 0,25 & 0,06 & 0,00 & 0,82 & 0,97 \\
\hline E-G & 0,97 & 0,98 & 0,99 & 0,91 & 0,00 & 0,95 & 0,00 & 0,00 & 0,00 & 0,00 & 0,00 \\
\hline E-H & 0,00 & 0,00 & 0,99 & 0,91 & 0,26 & 0,38 & 0,00 & 0,05 & 0,00 & 0,00 & 0,03 \\
\hline E-Ex & 0,97 & 0,98 & 0,99 & 0,91 & 0,00 & 0,42 & 0,00 & 0,00 & 0,00 & 0,00 & 0,00 \\
\hline F-G & 0,05 & 0,98 & 0,04 & 0,91 & 0,01 & 0,95 & 0,00 & 0,00 & 0,72 & 0,00 & 0,00 \\
\hline $\mathrm{F}-\mathrm{H}$ & 0,97 & 0,00 & 0,99 & 0,91 & 0,45 & 0,95 & 0,19 & 0,91 & 0,03 & 0,00 & 0,04 \\
\hline F-Ex & 0,97 & 0,98 & 0,99 & 0,83 & 0,00 & 0,95 & 0,00 & 0,00 & 0,39 & 0,00 & 0,00 \\
\hline G-H & 0,01 & 0,00 & 0,12 & 0,91 & 0,74 & 0,95 & 0,32 & 0,00 & 0,00 & 0,82 & 0,97 \\
\hline G-Ex & 0,97 & 0,98 & 0,99 & 0,16 & 0,74 & 0,95 & 1,00 & 0,11 & 0,07 & 0,36 & 0,97 \\
\hline $\mathrm{H}$-Ex & 0,54 & 0,00 & 0,99 & 0,91 & 0,03 & 0,95 & 0,20 & 0,00 & 0,72 & 0,82 & 0,97 \\
\hline
\end{tabular}

Notas: Os destaques em cinza indicam variação significativa $(\alpha<0,05)$. Tur.=Turbidez; RT= Resíduos Totais; $\mathrm{T}=$ Temperatura; $\mathrm{OD}=$ Oxigênio Dissolvido; FT= Fósforo Total; Ni-Nitrito; Na= Nitrato; $\mathrm{Am}=$ Nitrogênio Amoniacal; $\mathrm{CT}=$ Coliformes Totais; $\mathrm{CF}=$ Coliformes Fecais.

As marcações em coloração cinza dispostas na Tabela 01 indicam os valores de $p$ que expressam significância $(\alpha<0,05)$. Em suma, as variáveis químicas (pH, Oxigênio Dissolvido, Fósfoto Total, Nitrito, Nitrato, Nitrogênio Amoniacal) e microbiológicas (Coliformes Totais, Coliformes Fecais) foram responsáveis pela maior disparidade entre as nascentes. A partir disso, infere-se que as variáveis físicas (Turbidez, Resíduos Totais, Temperatura) não são tão significativas na detecção de alterações na qualidade da água das nascentes quanto as variáveis químicas e microbiológicas, apesar dos diferentes ambientais às quais estão expostas as nascentes em estudo. 


\section{DISCUSSÃO}

O fósforo total foi a única variável que não obteve variação significativa entre as nascentes, exceto entre as nascentes $D / C$ frente a nascente $H$ (TABELA 1). Esta, porém é a localização amostral com maior nível de impacto antrópico e juntamente com a nascente $G$, apresenta estado de conservação ambiental altamente degradado. Pelo exposto, não houve variação estatística significativa para a maior parte das variáveis estudadas entre as nascentes mencionadas ( $\mathrm{H}$ e $\mathrm{G}$ ) e o exutório da bacia, uma vez que estudos anteriores já indicam qualidade ambiental ruim de diversos pontos do Igarapé Dois de Abril, sobretudo na região de urbanização densa (ROCHA et al., 2018; SANTOS et al., 2017), como também é o caso dos locais em que se encontram as nascentes $\mathrm{H} \mathrm{e} \mathrm{G}$, as mais visualmente impactadas.

Como observado nos dados de turbidez (Figura 02a), as nascentes B, C, F, G, H e o exutório da microbacia ultrapassam o limite de 100 UNT que é o limite máximo estabelecido pela CONAMA 357/05. A turbidez é a capacidade de dispersão da radiação na água, é representada predominantemente por partículas em suspensão (ESTEVES, 2011). Dessa forma, a presença de grande quantidade de partículas na água indica contribuição de material alóctone.

A supressão da mata ciliar é um aspecto marcante em grande parte das nascentes em estudo, sobretudo nas nascentes que obtiveram maior índice de turbidez, o qual cerca de $40 \%$ das áreas de APP dos córregos e nascentes da área urbana de Ji-Paraná-RO são compostas por vegetação rasteira e 17\% por área urbana (ROCHA et al., 2018), tal realidade evidencia a condição insatisfatória da vegetação ripária dos corpos hídricos da região. De forma semelhante, Roboredo et al. (2016) relatam as condições insustentáveis de uma microbacia na porção sul da região Amazônica que apresenta áreas agrícolas, principalmente pastagem, que favoreceu para os baixos valores do índice de sustentabilidade aplicado na microbacia.

Os resultados apresentados em igarapés de pequeno porte por Oliveira et al. (2014) no interior de São Paulo indicaram que mesmo o corpo hídrico apresentando vegetação ripária e ausência de emissão de esgotos, a erosão é a principal causa para aumento da concentração de sólidos em suspensão. Nesse aspecto se enquadram as nascentes B e C, pois apesar de apresentarem vegetação relativamente preservada observou-se um processo contínuo de desbarrancamento das margens, bem como nas demais nascentes que obtiveram altos valores de turbidez. Conforme esse entendimento, Melo et al. (2017) obtiveram correlação mais forte entre a qualidade da água em relação à bacia como um todo do que em relação à zona ripária, demonstrando que a aplicação de práticas de gestão deve ser abrangedora a nível de bacia.

Ainda, Cunha et al. (2016) encontraram também na região de São Paulo resultados em que a turbidez da água em rios florestados é cerca de 5 vezes menor do que em rios urbanizados, bem como não obtiveram variação significativa nos períodos sazonais. Os autores citam que não basta que a vegetação esteja presente, mas que é necessário que esteja em alto estado de conservação para que gere efeitos na concentração de sólidos e turbidez. Ressalta-se que em F, G, H e no exutório também foi perceptível a emissão de esgoto, sendo esse um dos fatores que contribuíram para elevar a turbidez da água, fósforo, nitrito e nitrato da água, 
bem como entrado por Marmontel et al. (2018) em uma nascente no interior de São Paulo com emissão de esgoto identificada.

Quanto ao $\mathrm{pH}$ foi identificado um padrão sazonal, com valores próximos à neutralidade na estação seca e tendência à acidificação nas estações cheia e cheia/seca. Trabalhos desenvolvidos anteriormente na região tem demonstrado essa tendência, a exemplo Medeiros et al. (2017), Pereira et al. (2016) e Zuffo et al. (2013) com valores mínimos de pH de até 4,6; 5,12 e 4,7 respectivamente. Tal comportamento pode ser atribuído à formação de ácidos húmicos a partir da decomposição da matéria orgânica carreada pelas chuvas (ESTEVES, 2011). Os pontos que apresentaram menor amplitude foram os mais impactados quanto ao esgoto. No mesmo sentido Marmontel et al. (2018) encontraram valores mais ácidos para nascentes com influência de esgoto. Nesse sentido, a diluição do esgoto pode ter sido mais influente do que a variação sazonal, assim como sugerido por Oliveira et al. (2014).

Em relação ao OD, apesar de a norma estabelecer o limite mínimo de $5 \mathrm{mg} / \mathrm{L}$ deve-se ter em mente que as nascentes são pontos de afloração da água subterrânea e passam por pouca aeração. Ainda, de acordo com Esteves (2011) e Tundisi et al. (2008), as principais fontes de OD na água são a superfície de contato com a atmosfera e a produção primária. No entanto o contato pode não ser suficiente para oxigenação da água das nascentes.

Valores semelhantes foram encontrados por Butzke et al. (2015) para o igarapé Pintado, e Santos et al. (2017) ao longo do igarapé Dois de Abril no mesmo município em estudo, com valores mínimos em torno de 0,6 mg/L, 0,6 mg/L e 1,4 mg/L, respectivamente. Destaca-se que a concentração de OD foi correlacionada negativamente com a urbanização por Melo et al. (2017) em microbacias na região Sudeste do país.

Da mesma forma, Bezerra et al. (2014) encontraram condições insatisfatórias no igarapé Riachuelo, na área urbana no município de Ji-Paraná, com valores mínimos em torno de $3 \mathrm{mg} / \mathrm{L}$. Os autores atribuíram a baixa concentração de OD à presença de matéria orgânica originada por esgotos. Pereira et al. (2016) também encontraram baixas concentrações de OD na bacia do Rio Peixe Boi, no Pará e inferiram a causa ser a ocupação irregular das áreas de APP da bacia. Da mesma forma, no estudo conduzido por Roboredo et al. (2016) em uma microbacia no norte do estado do Mato Grosso os valores variaram de 3 a 1 mg/L, indicando que a baixa diluição do OD pode ser um problema regional.

Destaca-se que a nascente $C$ e $D$, se encontraram em condições de escassez de OD durante todo o período de estudo. Esta observação é especialmente preocupante pelo fato de que a dispersão de OD na água é de grande importância para a manutenção do equilíbrio aquático (ESTEVES, 2011). Concordantemente ao estudo conduzido por Zuffo et al. (2013) em ambientes lóticos amazônicos, a escassez de oxigênio nessas nascentes pode ter sido provocada pela vegetação em decomposição dentro do corpo d'água. Na nascente C, a carga orgânica é proveniente de pomares próximos, enquanto que na nascente $D$ é oriunda de plantas aquáticas.

$\mathrm{Na}$ Figura $2 \mathrm{~d}$ observa-se que todos os valores encontrados quanto à concentração de fósforo ultrapassaram o padrão máximo de $0,1 \mathrm{mg} / \mathrm{L}$ estabelecido pela CONAMA 357/05. Tais valores podem se devidos a não absorção pelas plantas, pela liberação de fosfatos na água solúveis na argila, que ocorre em 
regiões tropicais (ESTEVES, 2011), todavia além dos possíveis fatores naturais, o esgoto, a contaminação de área rurais com a entradas de excrementos bovinos e a contaminação difusa por parte da área antropizada infere diretamente no teor de fosforo (OLIVEIRA et al., 2014; ROBOREDO et al., 2016).

Assim, os valores aqui encontrados se pautam devido principalmente as influências das atividades antrópicas, como é observado nos pontos mais degradados, a exemplo das nascentes $E, F \mathrm{G}, \mathrm{H}$ e Exutório. Os dados representados na Figura 02, gráficos f e $\mathrm{G}$, apresentam os resultados da análise de nitrato e nitrito. Em alguns casos, como nas nascentes $B, C, D$ e E, não foi possível detectar a concentração de nitrato na água.

A nascente $\mathrm{G}$ foi a única que obteve valores relativamente altos, sobretudo nos períodos de cheia $\mathrm{e}$ na transição entre a cheia e a seca. Neste ponto foi possível registrar a emissão direta de esgoto não tratado por um estabelecimento de comércio de alimentos que possui um departamento de açougue. Tunsidi et al. (2008) apontam que esta é uma possível fonte da alta carga de nitrogênio em ambientes naturais.

Devido à carga considerável deste composto o teste estatístico indicou que tanto a nascente $\mathrm{G}$ quanto o exutório da bacia estão negativamente impactados quanto à concentração de nitrato, em relação aos outros pontos (TABELA 1). Ainda assim, a CONAMA 357/05 determina a concentração máxima de nitrato de cerca de $10 \mathrm{mg} / \mathrm{L}$. Desta forma, não foram obtidos resultados em desconformidade com o estabelecido pela norma em análise.

Ao contrário do comportamento do nitrato, na nascente $\mathrm{G}$ o nitrito foi maior no período seco e de transição entre seca e cheia. Santos et al. (2017), encontraram valores máximos de concentrações de nitrito em torno de 0,15 mg/L ao longo do igarapé Dois de Abril. Desta maneira, a concentração encontrada na nascente $\mathrm{G}$ durante o período de seca foi maior do que à jusante do corpo hídrico, possivelmente devido a nitratação.

A concentração excedente de nitrato e nitrito na nascente $G$ pode ter sido provocada pela nitrificação do nitrogênio amoniacal emitido pelo esgoto do estabelecimento comercial. Segundo Enrich-Prast (2005), tal processo envolve a oxidação do nitrogênio amoniacal em nitrito ou nitrato. Como observado nos gráficos estes compostos foram os mais abundantes neste ponto. Em altas concentrações o nitrito pode ser tóxico, acima de 10 mg/L (ESTEVES, 2011). A CONAMA 357/05 restringe o limite para 1 mg/L. Ainda assim os valores estiveram durante todo o estudo dentro do padrão determinado pela norma.

Conforme observado, a nascente $\mathrm{G}$ apresentou as maiores cargas de nutrientes dissolvidos e totais (Fósforo Total, Nitrato e Nitrito), sobretudo na estação seca/cheia. No período seco foi forte o processo de eutrofização neste ponto. Assim sendo, as altas concentrações encontradas desses nutrientes na estação seguinte podem estar relacionadas à decomposição de matéria orgânica morta proveniente dos organismos fitoplanctônicos.

A nascente citada é o único ponto que apresenta despejos de esgoto comercial, sendo esta a causa principal do desequilíbrio ambiental do ecossistema. Da mesma forma, demais estudos associam a maior carga de nutrientes e clorofila-a a pontos de amostragem com despejos de esgoto sanitário e industrial a montante (CORDEIRO et al., 2016; OLIVEIRA et al., 2014). 
Em relação aos parâmetros microbiológicos, a densidade de coliformes totais esteve além do estabelecido pela CONAMA 357/05, que é de 1000 colônias por $100 \mathrm{ml}$ de água (BRASIL, 2005). Destaca-se a alta densidade de Coliformes Totais nas nascentes $\mathrm{G}$ e H e também no exutório da bacia. Esses dados coincidem com os resultados obtidos por Butzke et al. (2015) e Rocha et al. (2018), na análise da água de igarapés em Ji-Paraná nos quais a densidade de coliformes totais atingiu 400000 UFC/100 ml e mais de 20 milhões de UFC/100ml, respectivamente. Resultado semelhante aos dados de Coliformes Totais é observado para a densidade de Coliformes Fecais.

Observam-se valores relativamente mais altos também no ponto $B$, sendo esta nascente considerada de boa preservação. Em conformidade com essa observação o teste estatístico indicou que está nascente diferiu das nascentes $C, D, E$ e F, e obteve semelhança com os pontos $G, H$ e com o exutório (TABELA 1). Nas amostragens periódicas foi constantemente observado lixo de higienização de sanitários no local da coleta. Infere-se que está ocorrência tenha elevado os níveis de contaminação da água por coliformes fecais.

As nascentes que apresentaram maior densidade de E.coli ( $B, G, H$ e exutório), exceto a nascente $B$, são aquelas que apresentam piores condições de preservação e encontram-se a menos de 5 metros de residências. Além disso, esses pontos sofrem intensamente com a descarga de esgoto, bem como toda a extensão urbanizada do igarapé.

Estudos demonstram a associação entre os altos índices de coliformes totais e fecais com áreas de maior densidade populacional e, sobretudo, com as cargas orgânicas lançadas em igarapés urbanos (OLIVEIRA et al., 2014; SOUZA et al., 2014). Além disso, Melo et al. (2017) e Pereira et al. (2016) encontraram correlação inversamente proporcional da qualidade da água e das áreas antropizadas. Da mesma forma Medeiros et al. (2017) identificaram densidade de coliformes fecais semelhante ao esgoto sanitário no rio Murucupi/PA.

Em geral, os resultados apontam para os diversos impactos sofridos pelas nascentes. Da mesma forma, estudos realizados na região urbana de Ji-Paraná indicam o alto nível de degradação dos córregos urbanos, dentre eles do Igarapé Dois de Abril (ROCHA et al., 2018; SANTOS et al., 2017). Tais conclusões vão de encontro aos resultados obtidos por Oliveira et al. (2017), no qual testes ecotoxicológicos comprovam os efeitos tóxicos em comunidades de microalga Chlorella vulgaris de igarapés urbanos em Ji-Paraná. De forma semelhante, um estudo ecotoxicológico com a espécie C. dubia desenvolvido por Vargas et al. (2014) demonstrou que até mesmo pontos localizados nas cabeceiras de igarapés urbanos no interior de São Paulo estavam fortemente impactados, de forma similar ao presente estudo.

Os impactos relatados são uma realidade constante nas cidades das diversas regiões brasileiras (CORDEIRO et al., 2016; MEDEIROS et al., 2017; OLIVEIRA et al., 2014; PEREIRA et al., 2016). A falta de planejamento territorial/ambiental e até mesmo de iniciativas preservacionistas tem como consequência a deterioração contínua dos recursos hídricos (TUCCl, 2016). De acordo com Oliveira et al. (2014) apesar da crescente necessidade pela melhora dos padrões ambientais o que se vê é uma fraca ligação entre os aspetos legais, a gestão e a tecnologia. 
Nesse sentido Tucci (2016) destaca a importância do planejamento e gestão das águas a nível municipal, e menciona juntamente com Malan et al. (2018) que países como Estados Unidos, Canadá e Austrália já vem adotando medidas de controle desde o fim da década passada, a exemplo de Boas Práticas de Manejo para conservação de nascentes e igarapés. Walsh et al. (2016), dispõe que tais medidas são efetuadas prioritariamente com foco na mitigação de inundações e poluição, mas que se deve priorizar também a função ecológica do corpo hídrico.

Desta forma, a revitalização dos corpos hídricos urbanos está ligada tanto a questões ambientais e de saúde pública quanto à manutenção do ciclo hidrossocial (TUNDISI, 2014), no qual a população tenha o direito cultural a utilizar como referência os corpos hídricos para lazer, recreação, bem como para atividades gerais de subsistência. Esta, porém, é uma realidade ainda distante da atual.

\section{CONCLUSÕES}

As nascentes monitoradas no presente estudo encontram-se em condições insatisfatórias, uma vez que foram observados impactos ambientais relativos aos aspectos macroscópicos do entorno e à qualidade da água. Foram encontradas desconformidades quanto à CONAMA 357/05 para as variáveis turbidez, oxigênio dissolvido, fósforo total e coliformes totais. Ademais, foram observados impactos negativos em todas as nascentes, até mesmo naquelas que se encontram em condições de relativa preservação ambiental.

Ademais, espera-se que o presente estudo possa servir como veículo de informação sobre as condições das nascentes de água do município e possa estimular projetos de recuperação de nascentes urbanas tanto por parte dos gestores públicos quanto dos demais envolvidos na gestão ambiental e territorial do município.

AGRADECIMENTOS: ao Conselho Nacional de Desenvolvimento Científico e Tecnológico (CNPQ) pelo apoio financeiro através da concessão da bolsa e à Universidade Federal de Rondônia pelo apoio técnico-estrutural.

\section{REFERÊNCIAS}

ABNT. NBR 12.772: Águas: Determinação de fósforo. Rio de Janeiro: ABNT, 1992a.

ABNT. NBR 12.619: Águas: Determinação de nitrito Método da sulfanilamida e N-(naftil)-etilenodiamina. Rio de Janeiro: ABNT, 1992b.

ANA. Atlas esgotos: despoluição de bacias hidrográficas. Brasília: ANA, 2017.

APHA. Standard methods for the examination of water and wastewater. 21 ed. Washington: APHA, 2005.

BEZERRA, R. R.; ANDRADE, N. L. R.. Variáveis químicas e biológicas do igarapé Riachuelo como indicadoras de poluição urbana na cidade de Ji-paraná (RO). Iniciação Científica: CESUMAR, v.16, p.163-169, 2014.

BUTZKE, K.; NASCIMENTO, E. L.; ROSA, A. L. D.; OLIVEIRA, G. A.; BASTOS, W. R.; MALM, O.; MENDONÇA, A. P.; FERREIRA,
R. F.; GEORGIN, G.. Avaliação de um igarapé impactado pela urbanização da cidade de Ji-Paraná (Rondônia): Igarapé Pintado. In: SIMPÓSIO BRASILEIRO DE RECURSOS HÍDRICOS, 21. Anais. Brasília: 2015.

CAPPS, K. A.; BENTSEN, C. N.; RAMÍREZ, A. P.. Poverty, urbanization and environmental degradation. Urban Streams, v.35, n.1, p.429-435, 2016. DOI: https://doi.org/10.1086/684945

CARMO, A. J. B.; ARAÚJO, R. R.; ANDRADE, N. L. R.; RIBEIRO, J. G. S.. Delimitação e caracterização morfométrica das bacias hidrográficas urbanas em Ji-paraná, RO. In: SIMPÓSIO DE RECURSOS HÍDRICOS DO NORDESTE, 13. Anais. Aracaju: 2016.

CONAMA. Resolução n.357: Dispõe sobre a classificação dos corpos de água e diretrizes ambientais para o seu enquadramento. Brasília: DOU, 2005. 
CORDEIRO, G. G.; GUEDES, N. M.; KISAKA, T. B.; NARDOTO, G. B.. Avaliação rápida da integridade ecológica em riachos urbanos na bacia do rio Corumbá no Centro-Oeste do Brasil. Ambiente e Água, v.11, n.3, 2016. DOI: http://dx.doi.org/10.4136/ambi-agua.1857

CUNHA, D. G. F.; SABOGAL-PAZ, L. P.; DODDS, W. K.. Land use influence on raw surface water quality and treatment costs for drinking supply in São Paulo State (Brazil). Ecological Engineering, v.94, p.516-524, 2016. DOI: https://doi.org/10.1016/j.ecoleng.2016.06.063

ENRICH-PRAST. Caminhos do nitrogênio em ecossistemas aquáticos continentais. In: ROLAND, F.; CESAR, D.; MARINHO, M.. Lições de Limnologia. São Carlos: Rima, 2005.

ESTESVES, F.A. Fundamentos de Limnologia. 3 ed. Rio de Janeiro: Interciência, 2011.

GOMES, J. B.; WEBLER, A. D.; AGUIAR, A. G.; AGUIAR, L. J. G.; NUÑES, M. L. A.. Conversão de florestas tropicais em sistemas pecuários na Amazônia: quais as implicações no microclima da região?. Revista Brasileira de Climatologia, v.17, n.11, p.67-81, 2015. DOI:

http://dx.doi.org/10.5380/abclima.v17i0.42879

MALAN, J. A.; FLINT, N.; JACKSON, E. L.; IRVING, A. D.; SWAIN, D. L.. Off stream watering points for cattle: Protecting riparian ecosystems and improving water quality?. Agriculture, Ecosystems and Environment, v.256, p.144-152, 2018. DOI:

https://doi.org/10.1016/j.agee.2018.01.013

MARMONTEL, C. V. F.; LUCAS-BORJA, M. E.; RODRIGUES, V. A.; ZEMA, D. A.. Effects of land use and sampling distance on water quality in tropical headwater springs (Pimenta creek, São Paulo State, Brazil). Science of the Total Environment v.622-623, p.690-701, 2018. DOI:

https://doi.org/10.1016/j.scitotenv.2017.12.011

MEDEIROS, A. C.; FAIAL, K. R. F.; FAIAL, K. C. F.; LOPES, I. D. S.; LIMA, M. O.; GUIMARÃES, R. M.; MENDONÇA, N. M.. Quality index of the surface water of Amazonian rivers in industrial areas in Pará, Brazil. Marine Pollution Bulletin, v.123, n.1-2, p.156-164, 2017. DOI: https://doi.org/10.1016/j.marpolbul.2017.09.002

MELO, K.; VALENTE, R. A.; RANDHIR, T. O.; SANTOS, A. C. A.; VETTORAZZI, C. A.. Effects of land use and land cover on water quality of low-order streams in Southeastern Brazil: Watershed versus riparian zone. Catena, v.167, p.130-138, 2018. DOI: https://doi.org/10.1016/j.catena.2018.04.027

OLIVEIRA, L. E.; SANTOS, T. A.; NEVES, A. S.; ASSIS, J. P. M.; NASCIMENTO, E. L.; BASTOS, W. R.; WEBLER, A. D.; AZEVEDO, S. M.; MENDONÇA, A. P.. Ecotoxicidade crônica em microbacias urbanas de Ji-Paraná/Ro. In: CONGRESSO BRASILEIRO DE LIMNOLOGIA, 16. Anais. Rio de Janeiro: 2017.

OLIVEIRA, P. C. R.; NOGUEIRA, M. G.; SARTORI, L. P.. Differential environmental impacts on small and medium size rivers from center of São Paulo State, Brazil, and regional management perspectives. Acta Limnologica Brasiliensia, v.26, n.4, p.404-419, 2014. DOI: http://dx.doi.org/10.1590/S2179-975X2014000400008
PEREIRA, B. W. F.; MACIEL, M. N. M.; OLIVEIRA, F. A.; ALVES, M. A. M. S.; RIBEIRO, A. M.; FERREIRA, B. M.; RIBEIRO, E. G. $P$.. Uso da terra e degradação na qualidade da água na bacia hidrográfica do rio Peixe-Boi, PA, Brasil. Rev. Ambiente e

Água, v.11, n.2, p.472-485, 2016. DOI:

http://dx.doi.org/10.4136/ambi-agua.1802

ROBOREDO, D.; BERGAMASCO, S. M. P.; BLEICH, M. P. Aggregate index of social-environmental sustainability to evaluatethe social-environmental quality in a watershed in the Southern Amazon. Ecological Indicators, v.63, p.337345, 2016. DOI:

https://doi.org/10.1016/j.ecolind.2015.11.042

ROCHA, V. N. L.; ANDRADE, N. L. R.. Relação entre Índice de Qualidade das Águas e densidade demográfica dasimétrica em igarapés urbanos amazônicos. Revista Ibero-Americana de Ciências Ambientais, v.9, n.2, 2018.

ROY, A. H.; CAPPS, K. A.; EL-SABAAWI, R. W.; JONES, K. J.; PARR, T. B.; RAMÍREZ, A.; SMITH, R. F.; WALSH, C. J.; WENGER, S. J.. Urbanization and stream ecology: diverse mechanisms of change. Urban Streams, v.35, p.272-277, 2016. DOI: https://doi.org/10.1086/685097

SANTOS, T. A.; PAVANELLO, L. F. S.; OLIVEIRA, L. E.; ASSIS, J. P. M.; GOMES, B. M.; MENDONÇA, A. P.; BASTOS, W. R.; NASCIMENTO, E. L.. Caracterização limnológica do igarapé Dois de Abril, Ji-Paraná, Rondônia (Amazônia Ocidental). In: CONGRESSO BRASILEIRO DE LIMNOLOGIA, 16. Anais. Rio de Janeiro: 2017.

SOUZA, M. M.; GASTALDINI, M. C. C.. Avaliação da qualidade da água em bacias hidrográficas com diferentes impactos antrópicos. Engenharia Sanitária e Ambiental, v.19, n.3, p.267-274, 2014. DOI: http://dx.doi.org/10.1590/S141341522014019000001097

SOUZA, C. L. R.; COSTA, V. B.; PEREIRA, S. F. P.; SILVA, D. C. M.; SARPEDONTI, V.. Impacts of urban life on water quality and fish larvae communities in two creeks of the Brazilian Amazon. Ambiente e Água, v.11, n.1, p.13-23, 2016. DOI: http://dx.doi.org/10.4136/ambi-agua.1763

TRIOLA, M. F.. Introdução à Estatística: Atualização da Tecnologia. 11 ed. Rio de Janeiro: LTC, 2013.

TUCCI, C. E. M.. Regulamentação da Drenagem Urbana no Brasil. REGA, Porto Alegre, v.13, n.1, p.29-42, 2016. DOI: 10.21168/rega.v13n1.p29-42

TUNDISI, J. G.. Recursos hídricos no Brasil: problemas, desafios e estratégias para o futuro. Rio de Janeiro: Academia Brasileira de Ciências, 2014.

TUNDISI, J. G.; MATSUMURA-TUNDISI, T.. Limnologia. São Paulo: Oficina de Textos, 2008.

UNESCO. Aguas residuales: El recurso desaprovechado. Paris: UNESCO, 2015.

VALENTE, O. F; GOMES, M. A.. Conservação de nascentes: produção de água em pequenas bacias hidrográficas. 2 ed. Viçosa: Aprenda Fácil, 2011. 
VARGAS, L.; ATHANÁSIO, C.; DUPONT, A.; COSTA, A. B.; LOBO, E. A.. Evaluation of water and sediment quality of urban streams in Santa Cruz do Sul County, RS, Brasil, using ecotoxicological assays. Acta Limnologica Brasiliensia, v.26, n.1, p.18-25, 2014. DOI: http://dx.doi.org/10.1590/S2179$\underline{\text { 975X2014000100004 }}$

WALSH, C. J.; BOOTH, D. B.; BURNS, M. J.; FLETCHER, T. D.; HALE, R. L.; HOANG, L. N.; LIVINGSTON, G.; RIPPY, M. A.;
ROY, A. H.; SCOGGINS, M.; WALLACE, A.. Principles for urban stormwater management to protect stream ecosystems. Urban Streams Perspectives, v.35, p.398-411, 2016. DOI: https://doi.org/10.1086/685284

ZUFFO, C. E.; NASCIMENTO, G. F.; ABREU, F. A. M.; CAVALCANTE, I. N.. Caracterização da Qualidade de Águas Superficiais em Rondônia. Anuário do Instituto de Geociências, v.36, n.2, p.25-39, 2013. DOI: https://doi.org/10.11137/2013 22539

A CBPC - Companhia Brasileira de Produção Científica (CNPJ: 11.221.422/0001-03) detém os direitos materiais desta publicação. Os direitos referem-se à publicação do trabalho em qualquer parte do mundo, incluindo os direitos às renovaç̃ões, expansões e disseminações da contribuiç̃o, bem como outros direitos subsidiários. Todos os trabalhos publicados eletronicamente poderão posteriormente ser publicados em coletâneas impressas sob coordenação da Sustenere Publishing, da Companhia Brasileira de Produção Científica e seus parceiros autorizados. Os (as) autores (as) preservam os direitos autorais, mas não têm permissão para a publicação da contribuição em outro meio, impresso ou digital, em português ou em tradução. 